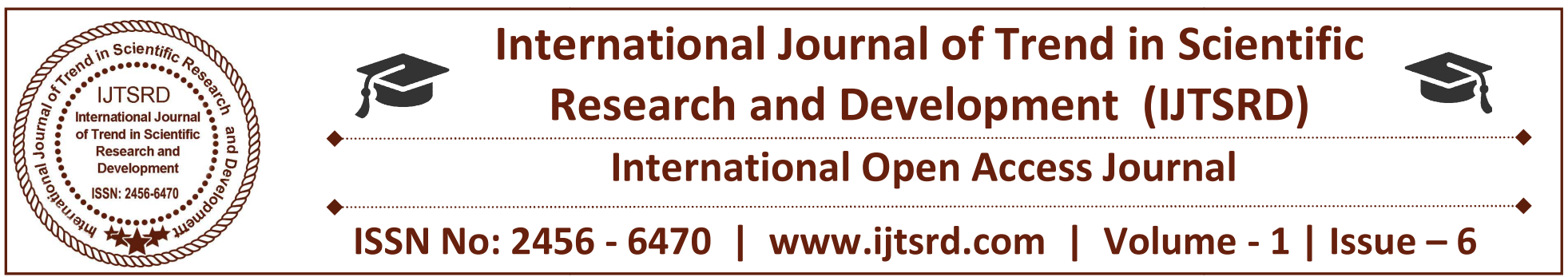

\title{
An Alternative Fuel for Future Bio Fuel
}

\author{
Dr. Renu Rastogi \\ Associate Professor, Department of Chemistry, \\ Brahmanand P.G. College, Kanpur
}

\begin{abstract}
Biofuels are gaining increased public and scientific attention, driven by factors such as oil price spikes, the need for increased energy security and concern over greenhouse gas emissions from fossil fuels. Most cars and trucks on the road today are fueled by gasoline and diesel fuels. These fuels are produced from oil, which is a nonrenewable fossil fuel. Nonrenewable fuels depend on resources that will eventually run out. Renewable resources, in contrast are constantly replenished and will never run out. Biomass is one type of renewable resource, which includes plants and organic wastes. Biomass Program researchers are studying how to convert biomass into liquid fuels for transportation, called biofuels. The use of biofuels will reduce pollution as well as the country's dependence on non-renewable oil.
\end{abstract}

Keywords - Biomass, Pollution, Biofuel, Energy.

\section{INTRODUCTION}

Today with growing awareness in industry, academia, and the general public of the need for sustainable development, the international chemistry community is under increasing pressure to change current working practices and to find pollution prevention alternatives. Global warming as a phenomenon affects all the nations and touches the whole humanity. The dangers of rising temperature, melting polar ice, deteriorating drought conditions and floods and intensifying heat waves have created keen interest among nations of the world for finding some solution of the problem.
The solar thermal and bio-mass conversion is seen as very efficient energy conservation processes in near future. Today our industrial civilization releases into the atmosphere far more carbon di-oxide than what can be absorbed by the greenery on land and water in the sea. $\mathrm{CO}_{2}$ level has been rising steadily from the eighteenth century and the rise has been particularly rapid during the last few decades. If the level of $\mathrm{CO}_{2}$ is not brought down, then human beings must be heading for "ecocide" - a term that has been coined by some experts which means self-destruction because of will full but unwise alteration of the environment.

The introduction of biofuels will be beneficial for the developed countries through energy security by reducing the dependence on fossil fuels and contributing to lower greenhouse gas emissions. Biofuels are meant to fight against climate change by decreasing our dependence on nonrenewable deposits of coal and petroleum. They are combustibles that come from renewable biomass which in turn is the material that comes from plants. Plants use the light energy from the sun to convert water and carbon dioxide to sugars that can be stored, through a process called photosynthesis. Organic waste is also considered to be biomass, because it began as plant matter. Researchers are studying how the sugars in the biomass can be converted to more usable forms of energy like electricity and fuels. The concept that bio-fuels will decrease the consumption of fossil fuels thus resulting in the reduction in greenhouse gases, requiring careful consideration. Current share of biofuels is around $1 \%$ which is proposed to be increased up to $5 \%$ by the year 2020. The World Bank has 
admitted the composition between food and fuel crops for land and water has asked the national governments to carefully assess economic, environmental and social benefits.

\section{Types of biofuels:}

Petroleum reserves are under stress to match the demand, and hence need to look for the alternate resource is on, that has to be cheaper and can make our environment green, and lower the greenhouse effects.

The use of alternate energy source is in demand in developing as well as developed countries. On one side resource of conventional fuels are limited, on another side they cause pollution at an alarming level. There are different forms in which we can obtain biofuels and they have quite a number of utilities too.

Bio-diesel: This is the most common type of biofuels found and used around the world. Biodiesel has emerged one of the alternative fuel for the future to save societies from catastrophes. Biodiesel is not only eco-friendly but also provides a renewable source. Research shows that use of Biodiesel reduces hydrocarbon emission by $50 \%$ and brings down cancer causing particulate matter levels by as much $94 \%$. Industrial production of bio-diesel is a chemical process based on transesterification of various oils using alkaline and acidic catalysts which reduce the soluble fraction of diesel particulate but not the solid carbon fraction, particulate tapes, and exhaust gas recirculation, or a potentially longer engine life. Blending about 20\% Bio-diesel provides higher rating, superior lubricity, significant emission reduction and less toxic emissions. Vegetable oil is used in several old diesel engines that have indirect injection systems. The oil is also used to create biodiesel which when mixed with conventional diesel fuel is compatible for most diesel engines.

Presently across the world safe use of bio-diesel with petro-diesel is envisaged, In India Bio-diesel has been introduced as B5 which is officially allowed. Soya bean oil, Sunflower rape seed oil, Palm Oil, Corn oil, animal fat and waste cooking oil are currently exploited commercially for the production of bio-diesel in some parts of the world. In India a conscious decision has been made by the government for non-edible oils, for fuels purposes so as to mitigate pressure on edible oils. Therefore the feed stock sources identified for Bio-diesel in India are non-edible oils obtained from plant species such as Jutropha curcas, Karanja (Pongania Pinnata) Mahua (Mahuca Indica) etc., and less expensive Lipid bearing materials. The development of other feed stock is also of the interest not only further increasing the economic viability of Bio-diesel, but also to increase the potential supply of this fuel.

Bio alcohol: Bio alcohols are biologically produced alcohols. Fermenting and distilling sugar crops, starch corps that has been converted into simple sugars or processing cellulose bio-mass can produce bio-alcohols. These bio alcohols are mainly bio-ethanol, bio-methanol and rare among these bio alcohols are propanol and butanol. Biobutanol can be used directly in a gasoline engine and hence can be considered as a direct replacement for gasoline. The butanol can be burned straight in the existing gasoline engines without any alterations to the engine or the car. It is also claimed that this butanol can produce more energy. Also butanol has less corrosive effect and is less soluble in water than ethanol. Bio-methanol can be produced from bio-mass and biodegradable fraction of waste and is equivalent to methanol from non-renewable resources. Fuel ethanol can be produced from direct fermentation of simple sugars or polysaccharides like starch or cellulose that can be converted into sugars. About $95 \%$ of ethanol produced comes from agricultural products. Ethanol is most commonly used biofuel in the world. The use of ethanol as bio-fuel is very common however the lack of sugars and its high prices decreased the value in subsequent years. Ethanol can be put to use in the petrol engines as a substitute for gasoline. Also it's mixing in gasoline in any ratio is very easy, The contemporary automobile petrol engines can work on mixture of gasoline and ethanol that have $15 \%$ of bioethanol. This mixture of gasoline and ethanol has more quantity of octane. This indicates that the engine would burn hotter and more efficiently. In high altitude areas, the mixture of gasoline and ethanol is used as a winter oxidizer and thereby atmospheric pollution is decreased.

Biogas: Biogas is created when organic material is anaerobically digested by anaerobes. During 
production there is a solid byproduct called digestate. This can be used as a biofuel or fertilizer. Biogas consists of methane. Landfill gas is created in landfills due to natural anaerobic digestion and is less clean form of biogas. Dried manure, charcoal and wood are some examples of solid biofuels.

Bioethers: These types of biofuel can improve the performance of engines when fuel/oxygen factor are considered. They can enhance the levels of fuel/oxygen. This factor ensures spontaneous and high temperature burning. On the whole, engine performance can be improved as a result of this.

$>$ Syngas: This form of biofuel can also be used in a number of equipments as a source of fuel. Diesel engines, turbines, combustible engines can make use of this fuel. The combined process of gasification, combustion and pyrolysis given rise to Syngas which is biofuel. Bio-syngas resulting from biomass gasification contains $\mathrm{CO}, \mathrm{H}_{2}, \mathrm{CO}_{2}$, $\mathrm{CH}_{4}$ and $\mathrm{N}_{2}$ in various proportion 12,13 . The average bio-syngas from a downdraft gasifier with air as oxidant contains $22.16 \% \mathrm{CO}, 17.55 \% \mathrm{H}_{2}$, $11.89 \% \mathrm{CO}_{2}, 3.07 \% \mathrm{CH}_{4}$ with $\mathrm{N}_{2}$ and other gases as balance.

\section{Environmental impacts of Biofuel}

If degraded and unproductive agricultural farm lands can be converted into biofuel sources of high diversity then a lot of economic and environmental benefits can be realized. Wildlife area can be restored, soil erosion can be prevented, the pollutants that are water borne can be significantly reduced and carbon dioxide from the atmosphere can be collected as beneficial carbon rich compounds for the soil. In this way the fertility of that land can be restored, thus making it useful again. The fast production of biofuel is encouraging a lot of research works for generating renewable and clean sources of energy. It was estimated that in the European Union biofuel powered vehicles would constitute $5.75 \%$ of the total number of vehicles. And the forecast for 2020 goes in this way that the number of exclusively biofuel powered vehicles would increase up to $10 \%$. New technologies are being built in order to capture the carbon dioxide from the atmosphere so as to produce biofuel supplying crops. In this way a significant amount of carbon dioxide can be removed from the atmosphere. This carbon dioxide can then be stored as solid carbonates under the earth or inside the geological formations or long term repositories.

\section{Limitations of Biofuel}

It has been found that biofuels have less energy output compared to fossil fuels of the same quantity. The burning of biofuels may not be leaving significant carbon footprints but the process of making the whole setup to produce biofuels can release a good amount of carbon dioxide into the atmosphere. The initial setup cost of any biofuel production unit will require a large amount of investments. There may also be chances of a big hike in the price of staple food crops since more has to be produced for the production of biofuels. A huge supply of water will be demanded for the cultivation biofuel producing crops.

Most vehicles are not yet adapted to be run on biofuels. They also generate an obnoxious smell which can be very unwanted in localities. As a result of this the plant has to be situated very far away.

\section{A step ahead}

If the technology of biofuel is developed full-fledged then it would be available at a much cheaper rate than fossil fuels. Biofuel can be manufactured from a variety of sources including waste and byproducts and it would encourage recycling. Biofuel is a renewable source of energy as crops and wastes are developed very often. Since biofuels are easily degradable, there are no associated huge risks with spills and its collection is also less expensive. This can easily stimulate economic growth in the field of agriculture and its local production would also ensure security.

Apart from the common uses of biofuel discussed earlier like running fuel for vehicles there are some innovative uses of biofuels, such as

1. Running pumps: The piston pump that can be easily pedaled and cranked, can be connected to a generator which is supplied by biofuel enabling this pump's working.

2. Biofuel charged cells: A fuel cell was developed which generate electricity from the byproducts of cooking oil and sugar. It may be possible in future to use these kinds of cells, to power mobile phones and laptops.

Besides the development of an efficient and economically viable technology for ethanol production from lignocellulose materials, other 
processes based on the use of microalgae and continuous reactors with immobilised cells have also been strongly evaluated and are being considered as promissory strategies for future development of this sector. Algae fuel, also called oilgae or third generation biofuel, is a biofuel from algae. Algae are low input and high yield feedstock to produce biofuels. As matter of fact, average biodiesel production yield from microalgae can be 10 to 20 times higher than the yield obtained from oleaginous seeds or vegetable oils. With higher prices of fossil fuels (petroleum's) there is much interest in agriculture (farming algae).

Macroalgae (seaweed) also have a great potential for bioethanol and biogas production. Three marine macroalgae (Chondrus crispus, Himanthalia elongate, Undaris pinnatifida) are used as solid raw material for direct base-catalyzed transesterifications. One advantage of many biofuels over most other fuel types is that they are biodegradable, and so relatively harmless to the environment if spilled.

By using the Fischer-Tropsch process, biosyn gas can be transformed to a synthetic petroleum substitute. Biomass to Liquid via Fischer-Tropsch (BTL-FT) synthesis is gaining increasing interests from academia and industry because of its ability to produce carbon neutral and environmental friendly clean fuels. Such kind of fuels can help to meet the globally increasing energy demand as well as the need for a eco-friendly fuel.

\section{References}

1) Luisa Gouveia, Ana Cristina Oliveira, JInd Microbiol Biotechnol, 36, 269-274, 2009.

2) L.Wei, et. al.,Trans. ASABE, 52, 21-37, 2009.

3) S.I. Mussatto, et. al., Biotechnology Advances, 28, 817-830, 2010.

4) http://www.biofuel.org.uk, Retrieved on 2011$05-25$

5) Y.R. Shah, et. al., Int J Cur Sci Res.57-62, 2011.

6) http://www.innovateus.net

7) L Bilinova, http://degruyter.com, 2015.

8) A.Lali, http://www.currentscience.ac.in, 2016. 